\title{
Formal Comment
}

\section{The Ecological Footprint Remains a Misleading Metric of Global Sustainability}

\author{
Linus Blomqvist ${ }^{1 *}$, Barry W. Brook ${ }^{2}$, Erle C. Ellis ${ }^{3}$, Peter M. Kareiva ${ }^{4}$, Ted Nordhaus ${ }^{1}$, \\ Michael Shellenberger ${ }^{1}$
}

1 Breakthrough Institute, Oakland, California, United States of America, 2 The Environment Institute and School of Earth and Environmental Sciences, The University of Adelaide, Adelaide, South Australia, Australia, 3 Department of Geography and Environmental Systems, University of Maryland Baltimore County, Baltimore, Maryland, United States of America, 4 The Nature Conservancy, Seattle, Washington, United States of America

The Formal Comment by Rees and Wackernagel [1] raises our concern that this exchange will confuse readers. For this reason, we aim to emphasize a few key points that we believe cannot be disputed. First, the entire global ecological overshoot (footprint of consumption in excess of biocapacity) results from carbon dioxide emissions reframed as the hypothetical forest area needed to offset these emissions. Plantations of fast-growing trees would, by-the-numbers, eliminate the global overshoot. Second, the ecological footprint's (EF) assessments for cropland, grazing land, and builtup land are unable to capture degradation or unsustainable use of any kind. Finally, we conclude from the above and the points made in our original paper [2] that we would be better off discussing greenhouse gas emissions directly in terms of tons of $\mathrm{CO}_{2}$-equivalent (and thus focus on solutions to emissions), and developing a more ecological and ecosystem process framework to capture the impacts humans currently have on the planet's natural systems. The appropriate scale for these indicators will, in many cases, be local and regional. At this level, the EF is a measure of net exports or imports of biomass and carbon-absorptive capacity [3]. Any city, for example, would show a deficit, as it relies on food and materials from outside. That in itself, as Robert Costanza has

\section{References}

1. Rees WE, Wackernagel M (2013) The Shoe Fits, but the Footprint is Larger than Earth. PLoS Biol 11(11): e1001701. doi:10.1371/journal.pbio.1001701

2. Blomqvist L, Brook BW, Ellis EC, Kareiva PM, Nordhaus T, et al. (2013) Does the Shoe Fit? Real versus Imagined Ecological Footprints. PLoS Biol 11(11): e1001700. doi:10.1371/journal.pbio. 1001700 noted, "tells us little if anything about the sustainability of this input [from outside the region] over time" [4].

\section{Author Contributions}

The author(s) have made the following declarations about their contributions: Wrote the paper: PK LB EE BB TN MS.

Citation: Blomqvist L, Brook BW, Ellis EC, Kareiva PM, Nordhaus T, et al. (2013) The Ecological Footprint Remains a Misleading Metric of Global Sustainability. PLoS Biol 11(11): e1001702. doi:10.1371/journal.pbio.1001702

Academic Editor: Georgina M. Mace, University College London, United Kingdom

Published November 5, 2013

Copyright: (C) 2013 Blomqvist et al. This is an open-access article distributed under the terms of the Creative Commons Attribution License, which permits unrestricted use, distribution, and reproduction in any medium, provided the original author and source are credited.

Funding: The authors received no specific funding for this work.

Competing Interests: This Formal Comment is a response to Rees and Wackernagel (this issue) by the authors of the original Perspective "Does the Shoe Fit? Real versus Imagined Ecological Footprints" (this issue).

* E-mail: linus@thebreakthrough.org

3. van den Bergh JCJM, Verbruggen H (1999) Spatial sustainability, trade and indicators: an evaluation of the "ecological footprint". Ecol Econ 29:61-72

4. Costanza R (2000) The dynamics of the ecological footprint concept. Ecol Econ 32:341-345.

Formal Comments are critiques of specific published articles. 